Final manuscript prepared for editing \& compilation - CCJ 15/3/2010 - AD updated 21/3/2010.

Finalised ccj 21/03/10

\title{
Urban geochemical mapping: a review of case studies in this volume
}

Christopher C. Johnson* ${ }^{1}$ and Alecos Demetriades ${ }^{2}$

${ }^{1 *}$ British Geological Survey, Keyworth, Nottingham, NG12 5GG, UK

${ }^{2}$ Institute of Geology and Mineral Exploration, Entrance C, Olympic Village, Acharnae 13677, Hellas

*Corresponding author email: ccj@bgs.ac.uk

Keywords: Geochemical mapping, methodologies, strategies, systematic surveys, targeted surveys, sample media, chemical analysis, data analysis, quality control, legislation, communication, future trends

\begin{abstract}
The development and history of geochemical mapping in urban areas is summarised. Urban geochemical surveys are generally classified as being systematic or targeted. A summary of the case studies presented in this book considers the sampling strategies, the chemical and data analytical methods applied. The use of the terms urban area, baseline, background and guideline values is explored. Important issues such as legislative drivers, communicating the results and future trends are also discussed.
\end{abstract}

\section{INTRODUCTION}

The choking black smoke from a diesel lorry has an obvious physical presence, but few appreciate its chemical composition or its potential to harm the environment, and the risks such exhausts pose to human health. The internal combustion engine and the resulting car traffic of our city streets have made a substantial contribution to changing the chemical make up of the city landscape. We generally do not see them, few understand them and most of us take the chemical elements very much for granted. So, why do we need to map the chemical elements in our urban environment, and how do we go about this task? The answers are covered in the thirty-three chapters of this book from many parts of the world, and particularly from Europe (Figure 1).

$<<$ INSERT FIGURE 1 NEAR HERE $>>$ 
Final manuscript prepared for editing \& compilation - CCJ 15/3/2010 - AD updated 21/3/2010. Finalised ccj 21/03/10

We need to protect the health of people living in urban areas, so they can achieve the quality of life that is the aspiration of every city dweller. In order to sustain the urban environment for future generations, the city has to be planned and managed so that populations are not "poisoned" by chemical elements and their compounds that are toxic. Unfortunately, much of this planning and management involves dealing with the legacy of industrialisation. We need to know what chemical elements are in our urban environment, and how this differs from the pre-urbanisation landscape. Once we have defined the urban chemical baseline, then we can monitor it for future changes, understand the sources of contamination and, with epidemiological and human health data, we will have a better understanding of the chemical elements and their compounds that damage our health.

The single-most important contributing factor to the chemical environment of an urban area is the underlying landscape on which a settlement or industry has been built - the soil, the overburden and the bedrock (Figure 2). The study of the distribution of chemical elements in materials at the surface of the earth is a fundamental part of geochemistry. For this reason, the vast majority of studies to map the chemical environment of urban areas have been led by applied geochemists. Mapping the chemical environment and geochemical mapping are synonymous terms.

\section{$<<$ INSERT FIGURE 2 NEAR HERE $>>$}

Geochemical mapping is a technique developed in the 1950s to provide information on the distribution of chemical elements in the surface environment. Its origin was mainly driven by economic imperative to find mineral resources. Early references to such work are found in the Soviet Union (Fersman, 1935) and later seen elsewhere (e.g., Lovering et al., 1950; Hawkes and Bloom, 1955). Regional geochemical mapping, as an aid to finding mineral resources, became a desirable national requirement and regional and national geochemical atlases started to appear in the 1960s and 1970s (Webb, 1978). In the last decades of the $20^{\text {th }}$ century, environment and health concerns were also increasingly being addressed by geochemical mapping (e.g., Thornton and Webb, 1979). Procedures for regional geochemical mapping are now well established and recommended global guidelines documented (Darnley et al., 1995; Salminen, Tarvainen et al., 1998). 
Final manuscript prepared for editing \& compilation - CCJ 15/3/2010 - AD updated 21/3/2010. Finalised ccj 21/03/10

Regional geochemical surveys have generally avoided urban areas. There are examples in regional geochemical atlases where the urban area is just represented by a blank hole, though usually associated by a heavy metal halo in the peri-urban area (Johnson and Ander, 2008; Chapter 8). Whilst regional geochemical mapping surveys are still actively being carried out in many parts of the world, particularly to boost the metalliferous minerals sector (e.g., the national geochemical mapping programme in Nigeria - Chapter 32), urban geochemical mapping is now regarded as one of the priorities of geochemical mapping.

Urban soil is a sink for a city’s polluting activities and, whilst current legislation may have substantially reduced these activities, a legacy of pollution can remain in the soil for 10s, 100s, or even 1000s of years. Both anthropogenic activity (e.g., the regeneration of former industrial sites or extreme natural events (e.g., the Katrina flooding of New Orleans - Presley et al., 2006) can redistribute previously "buried” harmful elements and compounds, so they become a much greater hazard. The legacy of contamination in European cities is a reflection of the long industrial history of this continent, and is the main reason why urban geochemical mapping was initiated here; a fact reflected in the large contribution of European case studies in this volume. It is interesting to note that many of the large cities of Africa, Asia, and South America do not have the industrial legacy of the cities of the western world. Batista et al. (Chapter 31) report that Beira (Mozambique) is typical for an African city lacking in a significant history of industrialisation. Instead of heavily polluted industrial areas, contamination is related to the pressures of population and the related deficient sanitary infrastructures.

An important point, made by some of the case studies, is that contamination is not always anthropogenic (e.g., Chapters 13 and 16). Mineral resources, such as coal and ironstone, factors in that were important in the industrialisation and urbanisation of urban areas, are also the source of enriched environmental levels of elements such as arsenic (As) and lead (Pb). The principal of “polluter pays", which is often enshrined in environmental legislation, cannot be applied to these, often significantly, large areas of natural contamination.

There have been several recent reviews of urban geochemistry, and their methods in the literature (e.g., Wong et al., 2006; Johnson and Ander, 2008; Albanese et al., 2008). Wong et al. (2006) looked at investigations from a trace element perspective, and discussed the development of the discipline of urban geochemistry. This is a term ascribed to Professor Ian 
Final manuscript prepared for editing \& compilation - CCJ 15/3/2010 - AD updated 21/3/2010. Finalised ccj 21/03/10

Thornton (Imperial College, London), who described it as research activities concerning the role of the geochemist at the interface of environmental geochemistry and urban pollution (Thornton, 1991). This volume does not set out to give a complete worldwide overview of urban geochemical mapping, but presents a generally comprehensive coverage of work currently taking place in Europe, and other selected locations from around the world. Significant omissions from this volume are a case study from Poland where has been a long established programme of urban geochemical mapping (Pasieczna, 2003), and any studies from Russia, though the influence of the former Soviet Union is reported in some of the case studies (e.g., Chapter 23 - Lithuania).

Johnson and Ander (2008) noted that a search of literature, reporting geochemical surveys since 2000, showed that urban geochemical mapping studies now surpass geochemical mapping investigations carried out for other purposes (e.g., mineral exploration). Contributions from Europe predominate, with an increasing number appearing from Asia in recent years.

The following sections summarise the chapters presented in this book, focusing on the important issues concerned with mapping chemical elements in the urban environment.

\section{METHODOLOGIES AND STRATEGIES FOR URBAN SAMPLING}

There is no standard or recommended methodology for mapping the chemical environment of urban areas in the way that there is for regional geochemical mapping (i.e., "A global geochemical database for environmental and resource management” - Darnley et al., 1995). The diversity of the factors that contribute to the individual characteristics of cities would prevent an overly prescriptive approach to urban geochemical mapping. However, in order to compare urban areas and, in particular, to conform to legislative requirements (e.g., European REACH directive (EC, 2006)), common sampling strategies and methodologies should be encouraged. The International Association of GeoChemistry for the purpose of harmonising urban geochemical survey techniques established in 2008 a Working Group on Urban Geochemistry; the motivating force behind this initiative is the Geochemistry Expert Group of EuroGeoSurveys, which has started an Urban Geochemistry project with the acronym URGE. After several discussions, in both the office and field, the field-sampling manual is being compiled. To begin with, ten cities in Europe will be investigated, using exactly the 
Final manuscript prepared for editing \& compilation - CCJ 15/3/2010 - AD updated 21/3/2010. Finalised ccj 21/03/10

same field sampling, sample preparation, and analytical methodologies in order to produce comparable results.

At the planning phase of any urban investigation, particularly if the results are going to be interpreted in the context of a regional baseline or guideline values, the methods must be compatible with those used to determine the baseline or guideline value. Important considerations include: the density and representivity of sampling; the sample media to be used; the depth of soil sampling and the size of the soil fraction used for the chemical analysis; the method of chemical analysis (especially whether to use a total or partial determination), and how to present and communicate the results to the stakeholders who will use them.

\subsection{Systematic versus targeted surveys}

Johnson and Ander (2008) classified urban geochemical mapping into two groups, namely, those concerned with systematic mapping the urban environment (systematic surveys) and those that had a more specific target or objective (targeted surveys) - see Table 1. Generally, the systematic surveys will precede the more targeted surveys, as the former usually identifies areas of possible contamination that require follow-up. Further, national geological surveys will generally be involved in the systematic surveys, whereas academic institutions will tend to focus on specific environmental problems. Lax and Andersson (Chapter 14) comment on how geological surveys are well suited for undertaking the role of geochemical baseline mapping, as they tend to be long-lived and have nationwide responsibilities.

\section{$<<$ INSERT TABLE 1 NEAR HERE $>>$}

Reasons given by case studies in this book for conducting urban geochemical mapping are summarised in Table 2. The aims and objectives for the chemical mapping are what determine the sampling strategy to be used. A generalised aim for mapping the chemical elements in the urban environment distilled from many of the case studies is "to obtain information about the distribution and sources of chemical elements and compounds that has practical applications in assessing health risks to people within the urban environment”. 
Final manuscript prepared for editing \& compilation - CCJ 15/3/2010 - AD updated 21/3/2010. Finalised ccj 21/03/10

Systematic surveys to determine the geochemical baseline of major urban areas are described by Chapter 13 (UK urban areas); Chapter 14 (urban areas Sweden); Chapter 17 (Berlin); Chapter 18 (Stassfurt); Chapter19 (Madrid); Chapter 20 (Tallinn); Chapter 21 (Prague); Chapter 22 (Ljubljana); Chapter 23 (urban areas of Lithuanian); Chapter 30 (Denver); Chapter 31 (Beira City), and Chapter 33 (Hong Kong). The geochemical baseline survey reported by Smith et al. for Denver, USA (Chapter 30) is unique amongst the case studies in that they are able to present and compare results from two baseline studies conducted in 1972 and 2005. On a smaller scale, Ďuriš (Chapter 21) reports on the changing concentrations of Pt, Pd and Pb in soil sampled near roads in Prague in both 1996 and 1999, Another original strategy for a systematic survey is that of Reimann et al. (Chapter 16), the Oslo transect, Norway. Whilst the surveys mentioned above systematically covered complete urban areas, usually on a kilometre square basis, Reimann et al. systematically sampled along a $120 \mathrm{~km}$ line (at $3 \mathrm{~km}$ intervals) across the city of Oslo, Norway, extending the line out of the urban area. The transect approach only requires a limited number of sample sites, so it is feasible to collect more sample materials, and is ideal as a pilot project or an orientation study.

Other investigations described in this volume have involved a mixture of both a systematic survey and some targeted follow-up. Albanese et al. (Chapter 24) describe baseline mapping of Campania region and its urban areas, Italy, but also focus on a specific brownfield site (Bagnoli). Demetriades (Chapter 25) has carried out a systematic mapping of the extensively polluted Lavreotiki peninsula and the Lavrion urban area, Hellas, using a multi-media approach, and has focused on environmental impact maps and the measures for environmental remediation and cost-benefit analysis.

Some European geological surveys, where geochemical baseline mapping of both regional and urban centres is long-established, have now moved on to specifically focus on legislative enforcement, health and specific targets of concern (Langedal and Ottesen (Chapter 12); Tarvainen and Jarva (Chapter 15); Vidojević and Gulan (Chapter 28); Ottesen et al. (Chapter 29). The Ottesen et al. chapter on clean soil at day care centres in Norway is very much a targeted survey, looking at a specific land use for a specific range of elements, and their sampling strategy reflects this - composite samples are not collected so as not to dilute any points of contamination. The case study presented by Batista et al., Beira City, Mozambique 
Final manuscript prepared for editing \& compilation - CCJ 15/3/2010 - AD updated 21/3/2010. Finalised ccj 21/03/10

(Chapter 31) is presented as a complete package of multidisciplinary investigations into the environment of an urban area.

The Norwegian Geological Survey has also been very active in targeting specific land uses, most notably child day care centres (kindergartens), where specific health risk are identified, particularly with regard to As, Pb, PAHs and PCBs (Chapters 10, 12 and 29). These studies are very much concerned with the impact on children's health of specific anthropogenic pollution, and proposed mechanisms for monitoring and remediating such contamination. Mielke et al. (Chapter 10) look at children’s health from a more global perspective.

In Finland, the Finnish Geological Survey (GTK) has an important role in providing the natural geochemical baseline as a reference for the assessment of soil contamination, as a result of a Government Decree on the "Assessment of Soil Contamination and Remediation Needs”. For this, GTK, in collaboration with local towns and municipalities, have compiled all geochemical baseline information into a "national geochemical baseline database" (Chapter 15); the legislative drivers for urban geochemical mapping are described in Section 6. However, it is worth noting here that the strategy behind geochemical mapping can very much depend on how close to government a geological survey or research institute is. Those organisations that have a close link with government (for example, residing within a government ministry) will generally have more statutory functions. Vidojević and Gulan (Chapter 28) describe their work very much in the context of the legal framework that operates in Belgrade, Serbia, and this work is integrated with determining the physical, as well as the chemical properties of the environment, particularly with respect to how contaminated soil impacts on ground water. Academics have a greater freedom to do smaller geochemical mapping projects, usually to support graduate or post-graduate training. The case study from Nigeria (Chapter 32) represents the work of university departments, specifically targeting industrial sites in south-western Nigeria.

\subsection{Sampling media}

The principal sample medium used by urban geochemical investigations is soil, mostly collected as a composited sample over several square metres. The sampling depth is quite variable with most describing their soil as topsoil (see Figure 3). Norwegian targeted investigations (Chapters 26, 27 and 29) collect "bare” surface soil from 0-2 cm, whilst systematic surveys tend use different sampling depths: 0-5 cm (Ďuriš - Chapter 21; Šajn et al. 
Final manuscript prepared for editing \& compilation - CCJ 15/3/2010 - AD updated 21/3/2010. Finalised ccj 21/03/10

- Chapter 22; Demetriades - Chapter 25); 0-10 cm (Gregorauskienè et al. - Chapter 23); 0-15 cm (Albanese et al. - Chapter 23; Smith et al. - Chapter 30; Abimbola and Olatunji - Chapter 32; Li- Chapter 33), or 0-20 cm (Birke and Rauch, - Chapters 17 and 18; Locutura and Bellan - Chapter 19; Bityukova and Birke - Chapter 20; Duriš - Chapter 21; Batista et al. Chapter 31); 5-20cm (Flight and Scheib - Chapter 13; Lax and Andersson - Chapter 14), and 0-25 cm (Tarvainen and Jarva - Chapter 15).

The British Geological Survey (BGS) (Chapter 13) for urban geochemical surveys now routinely collects from 3 depths: $0-2 \mathrm{~cm}$ - surface soil, $5-20 \mathrm{~cm}$ - topsoil, and 35-50 cm profile soil. The topsoil and profile samples correspond to the depth of sampling used for regional geochemical baseline surveys and, generally, due to the available budget, only the 5$20 \mathrm{~cm}$ samples are analysed. The BGS starting depth of $5 \mathrm{~cm}$ is a reflection of the fact that the surface organic litter, or root zone, is not collected as part of the topsoil sample. Many surveys describe the important influence that surface organic matter has on the distribution of trace elements, so the top surface litter/rootlet zone is discarded, and humus rich surface soil in woodland areas avoided (Chapter 18).

\section{$<<$ INSERT FIGURE 3 NEAR HERE $>>$}

Reimann et al. (Chapter 16) specifically targeted soil horizons (C-, B- and O-), and specify no depths. The advantage of using a soil horizon based approach is between sites you can compare similar layers of soil. The disadvantage is that it does generally require digging a soil pit to define clearly the horizons to be sampled. This is something that is not desirable if a large number of sites have to be sampled during the course of a day (usually with an auger), and sampling is most likely done by samplers with no great expertise in pedology. Investigations generally report the use of either a soil auger or spade/trowel to collect soil samples. Those using augers (e.g., Chapters 13, 20 and 33) are generally surveys collecting a large number of samples, whereas those using soil pitting have a requirement to study the soil profile in greater detail, and do not collect such a large number of soil samples (e.g., Lax and Andersson - Chapter 14; Tarvainen and Jarva - Chapter 15). Lax and Andersson note that the practical limit for pitting is about $1 \mathrm{~m}$, and it was important that the deep samples they collected (generally $>50 \mathrm{~cm}$ ) could be visually inspected in situ and were devoid of roots and Fe-hydroxides. Climatic conditions also play a role in the selection of the sampling method. 
Final manuscript prepared for editing \& compilation - CCJ 15/3/2010 - AD updated 21/3/2010. Finalised ccj 21/03/10

In Mediterranean countries, where soil is normally dry, pitting is the preferred method (e.g., Demetriades - Chapter 25).

Road deposited sediment (RDS) and household dust is another sample medium that has been used to good effect (e.g., Chapter 20, RDS - Madrid; Chapter 25 - house dust Lavrion).

Results from the Madrid RDS gave more diffuse patterns, but were generally consistent with soil data, although pollutant levels were much higher in the RDS. Locutura and Bel-lan (Chapter 20) conclude that soil is good for depicting historical and accumulated contamination, whilst RDS define current diffuse or local deposition of contaminants. The house dust results from Lavrion showed that, like the external environment, households were also very contaminated with high levels of $\mathrm{As}, \mathrm{Cd}, \mathrm{Pb}$ and $\mathrm{Zn}$ in house dust. Dust accumulating on snow enabled Gregorauskienè et al. (Chapter 23) to make comparisons with contamination found in underlying soil.

Other sample media are reported in the case studies. Vegetation in the form of twigs and leaves (Chapter 16), mosses (Chapters 14 and 16) and vegetables (Chapter 31) were used as part of the geochemical baseline mapping. Reimann et al. (Chapter 16) report that the urban footprint is best seen when using terrestrial moss as sample material, but caution that most plant materials did not function well as biomonitors for urban emissions. Terrestrial and aquatic mosses were sampled by Lax and Andersson (Chapter 14), who make the point that knowledge of one sampling medium cannot be used to predict how elements will behave in another medium. Analysis of living matter gives insights into geochemical processes not confined to soil. Results from the water moss showed clear differences in the chemistry of surface water of small streams in the studied urban area. Terrestrial moss comparison with existing data, where problematic (i.e., between Geological Survey of Sweden and the Environmental Protection Agency) illustrated the problems of using analytical data from two different sources.

Other sample media reported include marine sediment (Chapters 24 and 31), stream sediment (Chapters 23, 31 and 32), ground water (Chapters 25 and 28), sewage sludge, (Chapter 19), rocks, and waste materials from the mining and processing activities (Chapter 25). 
Final manuscript prepared for editing \& compilation - CCJ 15/3/2010 - AD updated 21/3/2010. Finalised ccj 21/03/10

\subsection{Parent material for urban area soil}

A fundamental control of the distribution of chemical elements in the urban environment is the underlying parent material (bedrock or overburden). The majority of case studies in this book seek to differentiate between the geogenic (i.e., those related to the underlying superficial and solid geology) and the anthropogenic sources of elements (Chapter 25). An understanding of the parent material (bedrock geology and superficial materials), and a comprehension of soil types, and their distribution in urban areas, are key parts of urban geochemical mapping. This is the reason, therefore, why geologists and geological surveys have a key role in these investigations. However, there is a growing trend for environmental scientists, with no background in geology or pedology, to be leading environmental investigations, and there is a danger that the most important control on chemicals in the urban environment - geology and soil types - is neglected in the interpretation.

\subsection{Defining the urban area and land use}

The case studies of this book emphasise the importance of considering land use in mapping the chemical environment. Placing the chemical results in the context of present and past land uses is essential to understanding the sources and distribution of anthropogenically introduced elements, since it plays an important part in the health risk assessments. Guideline or limiting values (see below) are generally related to a particular land use, often broadly defined as residential, recreational, or industrial. Specific land uses have been an important part of determining the strategy adopted by some of the case studies described in this volume (e.g., the work of the Norwegian Geological Survey in targeting day care centres).

Land use is also of fundamental importance in describing the difference between what constitutes an urban, as opposed to a regional geochemical survey. Johnson and Ander (2008) discuss the use of the term "urban area". There is a great range of definitions, and the criteria employed tend to reflect the need of the application to which the term urban is applied. Social scientists will probably use population density to define an urban area, though this varies from country to country. In the United Kingdom, one definition of an urban area is a settlement having a population >10,000 (Countryside Agency, 2004). The US Census Bureau defines urbanised areas as having a population >50,000 (US Census Bureau, 1995). Physical scientists tend to approach the use of the term urban area from the point-of-view of the builtup area and land use. In the UK, an urban area has generally been defined on the basis of the 
Final manuscript prepared for editing \& compilation - CCJ 15/3/2010 - AD updated 21/3/2010. Finalised ccj 21/03/10

built-up ornament on the 1:50,000 scale (UK) Ordnance Survey topographical maps (Johnson and Ander, 2008). In reality, most of the geochemical mapping surveys will use an administrative boundary to define the limits of their urban investigation.

The term suburb, or suburban, is generally used to mean the outer residential parts of urban areas, but extending to the less populated rural part. A number of authors in this volume have used the term peri-urban to describe the outer fringes of an urban area, predominantly rural land use, but may contain large out of town industrial sites (e.g., Chapter 19).

Knowing current and historical land use for an urban area is an integral part of an urban geochemical survey (Chapter 25). Land cover characterisation from satellite images formed the starting point for Batista et al. (Chapter 31) to determine the priority sampling targets in Beira (Mozambique). Langedal and Ottesen (Chapter 12) report on the regulation and administration of soil pollution in Trondheim (Norway), and for this, a historian was engaged to identify where earlier land use activities may have caused soil pollution.

\section{CHEMICAL ANALYSIS}

Allen et al. (Chapter 3) and Harrison and Reeder (Chapter 4) summarise the analytical options available for determining chemical elements and organic compounds in urban environmental samples with a focus on soil and sediment samples. Individual chapters, describe the analytical methodologies used in their case studies, including those for sample media other than soil and sediment. The most popular method of chemical analysis is inductively coupled plasma atomic emission spectrometry and inductively coupled plasma atomic mass spectrometry (ICP-AES and ICP-MS), following a variety of acid extractions to give partial or "near total” results (Chapters 14-19, 21, 22, 24, 25 and 30-33). For truly total determinations of a large range of elements X-ray fluorescence spectrometry (XRFS) techniques are used (Chapters 13, 14, 17, 18, 20, 21and 23), and more rarely instrumental neutron activation analysis (INNA) (Chapters 19 and 31), and atomic optical emission spectrometry (AOES) (Chapter 23). Atomic absorption spectrometry (AAS) is reported as being used by investigations (Chapters 17, 18, 21- 23, 28 and 30 - 32), mainly in connection with determining elements, such As and Hg.

From the above it can be seen that several investigations have used more than one analytical technique (Birke and Rauch (Chapters 17 and 18 - Berlin and Stassfurt); Locutura and Bel- 
Final manuscript prepared for editing \& compilation - CCJ 15/3/2010 - AD updated 21/3/2010. Finalised ccj 21/03/10

lan (Chapter 19 - Madrid). This obviously increases the analytical budget required for a project, but greatly helps in interpreting the behaviour and distribution of elements in the environment by comparing total and partial results. Locutura and Bel-lan conclude that partial extraction of elements helped to distinguish between natural and contamination sources and better define some of them.

A very active area of research is the importance of the bioaccessible fraction present in a soil, as opposed to the total amount. Methods for determining the bioaccessible fraction are described by Allen et al. (Chapter 3) though no case studies reported here have applied such methodologies. However, Flight and Schreib (Chapter 13) note that samples used from the urban geochemical baseline mapping in the UK have been utilised in investigations into bioaccessibility, demonstrating the importance of baseline mapping in stimulating downstream scientific research.

The strength of bonding of elements in the soil fraction has been determined in a number of case studies (Chapters 17 and 21) using the Tessier et al. (1979) methodology (see Chapter 3). An extraction procedure, based on that of Tessier et al. (1979), was used by (Gregorauskienè et al. - Chapter 23) for stream sediment from the Neris River, Lithuania. This can be a very useful aid to interpreting results, particularly with regard to the mobility of toxic elements and their impact on other urban compartments (e.g., ground water) if such anthropogenic pollution is considered to be migrating through the soil. Albanese et al. (Chapter 24) report how a weaker extraction (ammonium acetate-EDTA) than the Aqua Regia, used for the general survey, made $\mathrm{Cu}, \mathrm{Pb}$ and $\mathrm{Zn}$ readily bioavailable.

Lax and Andersson (Chapter 14) note that the analytical methods applied in their investigations are recommended by an environmental organisation (Swedish Environment Protection Agency) or in the case of Tarvainen and Jarva (Chapter 15), only Aqua Regia or concentrated nitric acid methods of extraction are acceptable for the database, as recommended by a national decree.

Comparing, however, studies from different urban areas of the world that have used different analytical methods and extraction procedures can be problematical. This will continue to be the case, if different national organisations prescribe different analytical protocols for guideline values and limits. The problem is further exacerbated by the fact that different 
Final manuscript prepared for editing \& compilation - CCJ 15/3/2010 - AD updated 21/3/2010. Finalised ccj 21/03/10

surveys will use different fraction sizes of soil for chemical analysis. The majority of surveys now use a $<2 \mathrm{~mm}$ soil fraction, though some, with good reason to compare with geochemical baseline materials analysed in earlier surveys, or in order to give the enhanced elements concentrations and contrasts usually seen in finer fractions, continue to use finer fractions for the urban surveys (e.g., Chapter 19 - Madrid) It is very important that the sample preparation and chemical analysis methodologies are described, when reporting investigations of chemical elements in the urban environment. Details, like size of fraction, method of chemical extraction and instrument used for the determination (along with detection limits) are important metadata that need to be included along with the results in the final database.

Norway leads the way with mapping organic compounds in the urban environment, and there are contributions from the Norwegian Geological Survey that provide valuable information about PCBs (Chapter 9), PAHs (Chapter 26) and PCDD/Fs (Chapter 27). The analysis of organic compounds is generally much more expensive than inorganic analyses, and applied geochemists with a background in using geochemical mapping for mineral exploration have little experience of determining and interpreting organic compound results. The sampling methodologies for media to be analysed for organic compounds are often more complex, particularly with regard to avoiding loss by volatilisation or contamination by the storage containers. Outside Norway, a number of surveys describe organic compound results (Birke and Rauch (Chapter 18 - Stassfurt); Locutura and Bel-lan (Chapter 19 - Madrid); Duriš (Chapter 21 - Prague); Albanese et al. (Chapter 24 - Bagnoli, Italy)). The experience of Locutura and Bel-lan was that many of the results for organic analyses were below detection, disappointing considering the expense of organic analyses - the PCB study in Madrid needed a greater sampling density. In view of the expressed apprehension of the Norwegian studies, with regard to the health risks of organic compounds in the environment, we must be concerned that similar high levels of PCBs may occur in children's play areas in other parts of the world (Mielke et al. - Chapter 10). The most comprehensive investigation of organic compounds outside of Norway is the case study for Stassfurt (Birke et al. - Chapter 18). They note the distribution of organic toxins is largely related to industrial activity.

Figure 4 shows a summary of the chemical elements described in the case studies presented in this volume. Copper, $\mathrm{Cr}, \mathrm{Ni}, \mathrm{Pb}$ and $\mathrm{Zn}$ are the most frequently reported elements. Modern analytical techniques allow a wide range of elements to be determined and reported. It is 
Final manuscript prepared for editing \& compilation - CCJ 15/3/2010 - AD updated 21/3/2010. Finalised ccj 21/03/10

important that a broad range of elements be analysed in systematic surveys of urban areas (Chapters 13 and 14), as undoubtedly additional chemical elements will increase in environmental importance, as new technologies introduce them to the environment. For example, the addition of Ce to fuel improves combustion and reduces soot formation and it is used, therefore, in a range of distillates, from jet fuel to diesel fuel (Jelles et al., 2001; OMG, 2010). Rare earth elements that are needed for electric cars, and communication equipment, will increasingly find their way into the urban environment. Neodymium (Nd) is used for lightweight magnets alloyed with $\mathrm{Tb}$ (terbium) and Dy (dysprosium). Lanthanum (La) is a component of hybrid car batteries, and the list will continue to increase.

\section{$<<$ INSERT FIGURE 4 NEAR HERE $>>$}

An element not always reported or investigated in urban centres is Au and both, Locutura and Bel-lan (Chapter 19 - Madrid) and Albanese et al (Chapter 24 - Napoli), comment that this element is a good indicator of anthropogenic contamination in urban centres. This has also been found by Reimann et al. (Chapter 16), who describe that the most pronounced urban peaks in moss samples were given by Au and Pt.

The determination of additional parameters, such as soil pH, conductivity, organic carbon content (loss-on-ignition) and particle size/textural analysis, is demonstrated by many of the case studies as being very important in understanding the distribution of chemical elements in the environment.

Albanese et al. (Chapter 24), in addition to chemical analyses produced in the laboratory, also present gamma-ray spectrometry data measured by a hand-held gamma-ray spectrometer at most soil sampling sites. Mineralogical analysis (SEM, etc.) has been reported in a number of case studies (Chapters 19, 21 and 30), and this gives direct evidence of the anthropogenic source of heavy metal anomalies. Isotopic analysis of Pb (using ICP-MS) to distinguish between anthropogenic and natural sources of $\mathrm{Pb}$ in the environment are reported by $\mathrm{Li}$ (Chapter 33), and as additional science projects not specifically discussed in this book Reimann et al., (2008) (Oslo) and Cicchella et al., 2008 (Napoli). 
Final manuscript prepared for editing \& compilation - CCJ 15/3/2010 - AD updated 21/3/2010. Finalised ccj 21/03/10

\section{QUALITY CONTROL}

All investigations that produce geochemical results require quality control in order that users of the data can be confident that they are fit-for-purpose. The fundamentals of quality control in sample analyses are described by Johnson (Chapter 5), and are based on the use of control samples - duplicates, replicates, standards and blanks, and a classical nested analysis of variance (ANOVA) procedure is utilised. It is also important to emphasise that quality control of geochemical data should be part of a broader quality assurance procedure for the whole project, covering all aspects of the work from start (field sampling) to finish (laboratory analysis).

All case studies describe the use of control samples and, whilst reports on the geochemical mapping may not include extensive details of quality control checking (e.g., duplicatereplicate plots), it is important that investigations state that the precision and accuracy of the results are considered as satisfactory. Conversely, chemical elements that fail quality control (i.e., if most of the variability between samples is ascribed to the analytical method rather than to between site variability), they should be identified and be discarded from the interpretation. Šajn et al. (Chapter 22), for example, provide the percentage deviation for elements from accepted values using standard reference materials, and an estimated variance for the elements. This is also described by Flight and Scheib (Chapter 13), who use ANOVA to demonstrate how much of the variance in analytical results for an element can be attributed to between site, within site and within sample (i.e., laboratory procedures) variability. Smith et al. (Chapter 30) report relative standard deviation (RSD) for reference materials.

The targeted survey discussed by Ottesen et al. (Chapter 29) emphasises need for good QC for urban investigations. Once surveys get involved in regulatory work, sampling and chemical analysis can be put out to tender, and many different organisations/commercial laboratories will end up doing the work over a period of time. It is essential to have good reference materials and QC procedures to be able to compare data between the many different small laboratories. Conversely, for large systematic surveys in which samples are collected and analysed by one organisation, quality control, whilst still an essential part of the survey, is less problematical, particularly if all the samples are collected in one field campaign, and analysed over a short period. 
Final manuscript prepared for editing \& compilation - CCJ 15/3/2010 - AD updated 21/3/2010. Finalised ccj 21/03/10

Reporting quality control information allows users of the data to understand how significant variations are between sites, something that is particularly important for elements where most results are near the lower limit of detection. Gregorauskienè et al. (Chapter 23) refer to the International soil-analytical exchange (ISE) programme that helped to ensure comparable results at an international level.

Demetriades (Chapter 6) takes QC a step further by describing a procedure for the estimation of total measurement uncertainty, using a robust analysis of variance technique (RANOVA). This is more appropriate for a wide range of concentration and multimodal distributions, where a change in measurement precision with concentration is expected and is strongly affected by a few outlying values.

\section{INTERPRETING AND PRESENTING THE RESULTS}

\subsection{Data Analysis}

Reimann et al. (Chapter 7) present a pragmatic approach to the interpretation of geochemical results by using the urban data from Berlin to illustrate how simple univariate and multivariate statistical analysis can be used effectively in the interpretation of geochemical data. They emphasise the point that chemical results from urban studies are spatially dependent, do not follow normal distribution, and usually have outliers that will have a significant effect on statistical analysis if not dealt with.

Many of those now involved in mapping the chemical elements of the urban environment, they have brought with them the interpretative techniques that are used for the interpretation of geochemical survey data, particularly that for mineral exploration purposes (Grunsky, 2010). In particular, many of the case studies in this volume have used principal component analysis (PCA) to identify element associations (Chapters 17 - 20, 22, 23, 30 and 31), and by plotting factor scores the spatial distribution of element associations can be delineated, and potential sources for anthropogenic contaminants recognised. Gregorauskienè et al. (Chapter 23) and Li (Chapter 33) use cluster analysis to determine element associations. Following on from the words of caution, expressed by Reimann et al. (Chapter 7) concerning data distributions and outliers, those using PCA and cluster analysis (CA) have taken care to detail 
Final manuscript prepared for editing \& compilation - CCJ 15/3/2010 - AD updated 21/3/2010. Finalised ccj 21/03/10

how they prepare data for PCA and CA. Andersson et al. (Chapter 27) use PCA to identify the possible sources for PCDD/Fs by using mass fraction conger profiles.

Because of the nature of geochemical data some authors (e.g., Lax and Andersson-Chapter 14) express a preference for using non-parametric methods. Simple summary statistics and univariate data plots can convey a lot of information to the data user. Boxplots (or box and whisker plots as they are sometimes referred to) are commonly used throughout this volume to depict how element concentration ranges can differ according to a particular classification (such as land use or parent material).

The terms baseline, background and guideline value are very important in the mapping of the chemical elements and their definition requires further discussion.

\subsubsection{Geochemical Baseline}

The term baseline, in a geochemical context, was used by Tidball et al. (1974) in a study of sagebrush and soil from Montana Wyoming, USA. It was a statistical definition based on the central 95\% of recorded values. Another earlier use of the term baseline, with respect to geochemical mapping, was from Newfoundland and Labrador as a measurement of environmental change (Davenport et al., 1993). It is a term that is now in widespread use in geochemical literature, reflecting the shift away from geochemical mapping's previously principal use in mineral exploration to environmental applications. The need for geochemical baselines is described in global initiatives, such as the FOREGS's (Forum of European Geological Surveys) European geochemical baseline project (Plant et al., 1997; Salminen et al., 1998). As part of an International Geological Correlation Programme (IGCP) (projects 259 and its successor 360 ), where internationally agreed protocols and procedures for geochemical baseline mapping were developed. Salminen and Tarvainen (1997) attribute the official introduction of the term geochemical baseline to the IGCP 360 project, though according to Salminen and Gregorauskienè (2000), the term geochemical baseline was not well defined at that time. The following definition of a geochemical baseline is based on that used by the Forum of European Geological Surveys (FOREGS) Geochemical Baseline Mapping Group: 
Final manuscript prepared for editing \& compilation - CCJ 15/3/2010 - AD updated 21/3/2010. Finalised ccj 21/03/10

"A geochemical baseline is the concentration at a specific point in time of a chemical parameter (element, species or compound) in a sample of geological material. It is a fluctuating surface rather than a given value”.

The geochemical baseline of element/compound $\mathrm{X}$ can be defined as a function of the methodology used to determine it:

\section{Baseline $X=f$ A $, B, C, D \ldots\}$}

for 1 to $\mathrm{n}$ samples from different locations at a specified point in time, where

$\mathrm{A}=\mathrm{a}$ defined media type,

$\mathrm{B}=$ a documented sampling method,

$\mathrm{C}=$ a documented sample preparation protocol, and

$\mathrm{D}=$ a documented analytical method.

A geochemical baseline simply reports the chemical state of the surface environment, exactly as it is, with no interpretation or partitioning of the data. The geochemical baseline is defined at a specific point in time.

Defining the geochemical baseline as a function in this way emphasises the fact that different methodologies will give different baselines. Hence, the need for standardised methodologies, if geochemical baselines between different projects and areas are to be compared.

When geochemical mapping in areas of little anthropogenic activity, with the exception of catastrophic events such as volcanic eruptions or extensive flooding, the geochemical baseline changes slowly in response to natural changes in an order of magnitude of decades or centuries. Changes to the urban geochemical baseline, as a result of constant anthropogenic activity, would be anticipated as being more rapid, so the time component is a more important factor (Johnson and Ander, 2008).

\subsubsection{Geochemical Background}

In the context of the urban environment, the geochemical background can be defined as: " $A$ relative measure to distinguish between natural element or compound concentrations and 
Final manuscript prepared for editing \& compilation - CCJ 15/3/2010 - AD updated 21/3/2010. Finalised ccj 21/03/10

anthropogenically-influenced concentrations in real sample collectives" (Matschullat et al., 2000). This can be expressed as a simple equation:

\section{URBAN BASELINE = BACKGROUND + Anthropogenic Contribution}

This is a fundamental equation in the interpretation and modelling of urban geochemical data. In the absence of any or negligible anthropogenic contribution the urban baseline will be equivalent to the background, and many chapters in this volume use the principle that outside of urban areas we can define the "natural" baseline (Chapters 13 and 15). The caveat being that the "natural" geochemical baseline around urban areas needs to have similar soil types and underlying parent material, as those upon which the urban area has been developed. In the equation above, if the "natural" geochemical baseline replaces the term background, then the anthropogenic contribution in an urban area can be estimated by subtracting the "natural" baseline from the urban baseline. In reality, this is a more complex estimation, because the background may be made up of many contributing geochemical populations (caused by variations in underlying parent material, for example), and the anthropogenic contribution is likely to be from multiple sources. Statistical methods for distinguishing baselines and backgrounds are discussed by Lima (2008) and Albanese et al. (2008).

\subsubsection{Guideline or Intervention values}

Important values cited in many of the case studies in this book are the guideline or intervention values that can be applied to define the concentrations at which potentially hazardous elements may pose a risk to human health. These values, often enshrined in legislation, are determined after lengthy consultations by multi-disciplinary teams to which applied geochemists make an important contribution. A good example of how soil guideline values (SGVs) are derived is given by the UK Environment Agency (EA, 2009).

\subsubsection{Ratios and indices}

The use of ratios and indices to demonstrate anthropogenic enrichment and spatial distribution is presented in a number of case studies, using quite a variety of approaches. An important parameter in these ratios and indices is some definition of a background value and, for anthropogenic contaminants with a health risk, a guideline value, or limit which may be legally enforceable. 
Final manuscript prepared for editing \& compilation - CCJ 15/3/2010 - AD updated 21/3/2010. Finalised ccj 21/03/10

Flight and Scheib (Chapter 13) use the ratio of element median values in urban soil over the element median value from regional data from soil overlying the same geological unit (Triassic sandstone) to define an enrichment factor, which is plotted for 38 elements giving a "geochemical fingerprint" for the urban area. Birke and Rauche (Stassfurt - Chapter 18) use the ratio $\mathrm{Al} /(\mathrm{Ca}+\mathrm{Mg}+\mathrm{K})$ to indicate buffering capacity of soil. This case study also uses a ratio of the measured value to the legal limit to define areas of heavy metal enrichment. The legal limits are prescribed by BBodSchV (1999) and summarised in tables given by Birke and Rauche.

Bityukova and Birke (Chapter 20) present an enrichment index (EI), calculated by averaging the ratios of element concentration in urban topsoil divided by the corresponding mean of each elements for arable soil in North Estonia from the Baltic Soil Survey (Reimann et al., 2000, 2003). The EI index can be plotted on a map to indicate where elements have been enriched.

Tarvainen and Jarva (Chapter 15) define the upper limit of geochemical baseline variation for element $\mathrm{X}\left(\mathrm{BL}_{\mathrm{X}}\right)$ as:

$$
\mathrm{BL}_{\mathrm{X}}=\mathrm{P}_{75}+1.5 \mathrm{x}\left(\mathrm{P}_{75}-\mathrm{P}_{25}\right)
$$

where

$\mathrm{P}_{75}=75^{\text {th }}$ percentile of element $\mathrm{X}$ concentrations, and

$\mathrm{P}_{25}=25^{\text {th }}$ percentile of element $\mathrm{X}$ concentrations.

Demetriades (Chapter 11) demonstrates that geochemical data can be applied to hazard and exposure assessment, commencing by defining a soil contamination index (CI), which is calculated using site specific soil action levels (SALs). The concentration of each chemical element at a sampling site is divided by its respective SAL (for residential land use) to give a concentration ratio, where the baseline concentration ratio is represented by a value of 1 . The $\mathrm{CI}$ is estimated for each site by summing up the concentration ratios of each element and subtracting the sum of the baseline concentration ratios for each element which, as the baseline concentration ratio equals 1 , is equal to the number of elements. A CI $>0$ indicates contamination by one or more elements. Demetriades also describes other indices, such as 
Final manuscript prepared for editing \& compilation - CCJ 15/3/2010 - AD updated 21/3/2010. Finalised ccj 21/03/10

"hazard index", "exposure index, "cost index” for the best available technologies for the remediation of contaminated land, and a "benefit index" to quantify the benefit of remediating an area.

Gregorauskienè et al. (Chapter 23) use a concentration coefficient, $\boldsymbol{K}_{\boldsymbol{k}}$, which is calculated as an element's concentration at a site divided by its background value. They also define a contamination index

$$
Z_{d}=\sum K_{k}-\mathrm{n}+1
$$

where

$\mathrm{n}=$ number of contaminant elements and a contaminant element is defined as having a value $\boldsymbol{K}_{\boldsymbol{k}}>1$ - only contaminant element concentration coefficients are summed.

The contamination index is plotted to define contaminated areas in Lithuanian cities. Sickness rates for groups of children were investigated in the context of $\boldsymbol{Z}_{\boldsymbol{d}}>16$. The level of health risks are defined using a $\boldsymbol{Z}_{\boldsymbol{d}}$ classification. For values of $\boldsymbol{Z}_{\boldsymbol{d}}<16$ the health risk is considered acceptable, $\boldsymbol{Z}_{\boldsymbol{d}}=16-32$ - medium risk, $\boldsymbol{Z}_{\boldsymbol{d}}=32-128$ - high risk and $\boldsymbol{Z}_{\boldsymbol{d}}>128-$ extremely high risk. A ratio called coefficient of risk $\left(\boldsymbol{K}_{\boldsymbol{0}}\right)$ is also defined by dividing an element concentration by a maximum permitted concentration (MPC) introduced as a health standard in Lithuania in 2004. The higher the value of $\boldsymbol{K}_{\mathbf{0}}$ the greater the perceived risk to health. Gregorauskienè et al. also used $\boldsymbol{Z}_{\boldsymbol{d}}$ to show the distribution of different geochemical element associations, classified as being chalcophile, siderophile, or lithophile.

Abimbola and Olatunji (Chapter 32) use a geoaccumulation index $\left(\mathrm{I}_{\text {geo }}\right)$ defined by Muller (1981) and an enrichment factor (EF).

$$
\mathrm{I}_{\mathrm{geo}}=\log _{2} \mathrm{Cn} /(1.5 \times \mathrm{Bn})
$$

where

$\mathrm{Cn}=$ measured concentration of the element in the sample, and

$\mathrm{Bn}=$ geochemical background value or soil guideline value . 
Final manuscript prepared for editing \& compilation - CCJ 15/3/2010 - AD updated 21/3/2010.

Finalised ccj 21/03/10

The enrichment factor,

$$
\mathrm{EF}=\left(\mathrm{Cn}_{\text {(sample })} / \mathrm{C}_{\text {conservative element }}\right) /\left(\mathrm{Cn}_{\text {(background) }} / \mathrm{C}_{\text {conservative background }}\right)
$$

where

$\mathrm{Cn}_{\text {(sample) }}=$ concentration of element in the sample,

$\mathrm{C}_{\text {conservative element }}=$ concentration of conservative element (e.g., Al) in the sample,

$\mathrm{Cn}_{\text {(background) }}=$ concentration of element in background sample, and

$\mathrm{C}_{\text {conservative background }}=$ concentration of the conservative element in the background sample.

These indices can be plotted as a bar chart or as a map (Abimbola and Olatunji).

A soil pollution index (SPI) that uses the Dutch target concentrations is used by Li (Chapter 33), i.e.,

$\mathrm{SPI}_{\mathrm{i}}=\left(\sum_{\mathrm{j}} \mathrm{MC}_{\mathrm{i}} / \mathrm{TC}_{\mathrm{j}}\right) / \mathrm{N}$

where

$\mathrm{i}=$ number of sampling locations,

$\mathrm{j}=$ heavy metals that are highly enriched,

$\mathrm{MC}_{\mathrm{i}}=$ metal concentration at the $i^{\text {th }}$ sampling location,

$\mathrm{TC}_{\mathrm{j}}=$ Dutch target concentration of $\mathrm{j}^{\mathrm{th}}$ metal that are highly enriched, and

$\mathrm{N}=$ the number of trace metals that are highly enriched.

The SPI can be plotted as an interpolated map and interpreted with other data layers in a GIS.

Lax and Andersson (Chapter 14) with chemical data for both topsoil and deeper profile soil are able to demonstrate the differences in element concentrations with soil depth. This is done by using a ratio of the topsoil to subsoil element concentrations, and they also looked at 
Final manuscript prepared for editing \& compilation - CCJ 15/3/2010 - AD updated 21/3/2010. Finalised ccj 21/03/10

element concentrations based on soil texture (sandy versus clayey). PAH ratios (fluoranthene/(fluoranthene + pyrene) and Indeno(1,2,3-c,d)pyrene/(Indeno(1,2,3-c,d)pyrene + benzo(g,h,i)perylene)) are used by Jensen et al. (Chapter 26) as proxies for different PAH sources.

\subsubsection{Map presentation}

A standard method of presenting geochemical baseline data is as interpolated colour gridded images, and many of the case studies in this volume have examples of such maps. These are discussed by Reimann et al. (Chapter 7), who caution that colours have different meanings in different cultures, and some individuals are blind to certain colours. Flight and Schreib (Chapter 13) and Smith et al., (Chapter 30) refer to the problems associated with over interpolating in urban areas, something that can blight property prices and cause local inhabitants much anxiety. Their preference for displaying geochemical results in urban areas is to use point symbol maps.

Albanese et al. (Chapter 24) present their data for the Napoli area as colour composite maps in which element associations (groups of three selected elements, e.g., $\mathrm{Cu}, \mathrm{Pb}$ and $\mathrm{Zn}$ ) take on a value representing the three primary colours red, green and blue. A composite map has colours generated according to the relative proportions of each element. A site where all three elements are high will plot in shades of white readily highlighting areas that are contaminated.

Several of the case studies report the production of urban geochemical atlases to present the geochemical results (Chapter 23 - Lithuania; Chapter 24 - Campania Region, Italy; Chapter 25 - Lavrion; Chapter 28 - Environmental Atlas of Belgrade), and the extensive Polish study, which is not reported here (Pasieczna, 2003). The use of GIS (e.g., ArcGIS) has transformed the way applied geochemists have been able to interpret and present their urban data. It is possible to display the geochemical data in the context of many other data layers, such as land use, population density, epidemiological information, and as has been done by $\mathrm{Li}$ (Chapter 33), annual average daily traffic data. The main deliverable of urban mapping projects, rather than being the geochemical map, is a GIS project that brings together the data and information from many disciplines. 
Final manuscript prepared for editing \& compilation - CCJ 15/3/2010 - AD updated 21/3/2010. Finalised ccj 21/03/10

Risk to health is an important outcome from projects mapping the chemical environment. Therefore, maps that present the data in terms of hazard and exposure assessment, as well as risk, are necessary for the administrative authorities and city planners. Demetriades (Chapters 11 and 25) in the Lavrion urban geochemistry study presents a variety of maps that add much more information to the basic geochemistry baseline that are used for risk assessment and decision making. Using a multi-criteria algorithm hazard and exposure maps are constructed, which show the respective values on a 50 x $50 \mathrm{~m}$ grid over the whole Lavrion study area. For environmental management three additional maps are produced, using the same grid, (i) a cost index map shows the cost of remediation using appropriate technologies according to contamination type; (ii) a benefit index map indicates the benefit for remediation, and (iii) a cost/benefit map is use in the decision making process of prioritising remediation.

\section{LEGISLATION}

The impact of chemicals in the urban environment on human health, and how it affects the quality of life for the city dweller, has now been the subject of scientific research for many years. However, it generally takes major environmental impact events such as the realisation that we are poisoning our children in their playgrounds (Chapter 10), to encourage governments to bring in legislation, and fund geochemical mapping projects in response to strong public opinion.

The European Union in order to protect Europe's landscapes, ecosystems and the environment has established a number of directives. Table 3 shows a number of these directives, summarising their objectives, and the necessity of harmonised geochemical baseline data across political borders indicated.

\section{$<<$ INSERT TABLE 3 NEAR HERE $>>$}

In the United Kingdom, for example, there was a very significant increase in the licensing of BGS urban geochemical baseline data prior to the Part IIA of the Environmental Protection Act 1990 coming into force in 2000, when local municipal authorities were legally required to identify contaminated land. This was anticipated in the urban mapping programme in England and Wales in the 1990s (Fordyce et al., 2005). 
Final manuscript prepared for editing \& compilation - CCJ 15/3/2010 - AD updated 21/3/2010. Finalised ccj 21/03/10

From the case studies in this volume, there is clearly a wide variety of guideline values that relate to national environmental organisations or legislation. Birke and Rauche (Chapter 18 Stassfurt) cite Federal Soil Protection and contaminated sites regulations for legal limits (BbodSchV, 1999) that are used in the presentation and interpretation of geochemical data (inorganic and organic) from Stassfurt, Germany. In the UK, the Environment Agencies (EA) soil guideline values are used by Flight and Scheib (Chapter 13) (EA, 2009). Whilst in Lithuania, maximum permitted concentrations (MPC) for hazardous substances in soil were introduced in 2004 (Chapter 23). In Madrid (Chapter 19), advisory guidance levels for element concentrations in soil (based on land use) have not yet been established. The present system is based on the use of median and reference levels at 95 and 99\% confidence levels these are related to specific soil types. Maximum allowed concentrations in soil and water for irrigation (As, B, Cd, Cr, Cu, F, Pb, Hg, Ni and Zn), specified by OGRS (1994) for Serbia are described by Vidojević and Gulan (Chapter 28), though they used Dutch standards for organic compounds. They also discuss the reporting requirements for project investigations.

In Finland, a Government Decree on the assessment of soil contamination and remediation needs came into force in 2007. Assessment of soil contamination is based on a site specific estimate of the risk to human health and the environment, and the geochemical baseline concentrations of harmful substances in soil refer to both the natural and urban backgrounds, the latter with superimposed anthropogenic input (Chapter 15). National threshold values are given in the Finnish Decree (214/2007) (Finnish Government Decree, 2007) for As, Cd, Co, $\mathrm{Cr}, \mathrm{Cu}, \mathrm{Ni}, \mathrm{Pb}, \mathrm{Sb}, \mathrm{V}$ and $\mathrm{Zn}$ (determined by Aqua Regia extraction for different types of topsoil (till, sand and clay).

There are no legislative guideline limits for soil contaminants in Hellas. Hence, site-specific residential and industrial soil action levels (SALs) for the Lavrion urban area had to be developed (Nikolaidis et al., 1999). For the residential and industrial areas, the risk assessment guidelines of the United States Environmental Agency (US EPA, 1996) and risk assessment equations developed by the State of Connecticut (US Connecticut, 1997) respectively, were used (Demetriades - Chapter 11). In Sweden, guideline values for contaminated soil are published by the Swedish Environment Protection Agency (Swedish EPA, 2008) (Chapter 14). Smith et al. (Chapter 30) use US EPA soil screening levels for selected elements - these are not intended, however, to represent action or clean-up levels. 
Final manuscript prepared for editing \& compilation - CCJ 15/3/2010 - AD updated 21/3/2010. Finalised ccj 21/03/10

In the soil pollution index, calculated for Hong Kong (Chapter 33) the Dutch target concentrations (Swartjes, 1999) for the heavy metals were used. In Mozambique, reference is made to admissible standards of the Drinking Water Quality Regulation from the Health Ministry of Mozambique (Chapter 31). Duriš (Chapter 21) reports that in soil maximum values of $\mathrm{As}, \mathrm{Cd}, \mathrm{Cu}, \mathrm{Ni}, \mathrm{Pb}$ and organic pollutants (PAH and PCB) exceed the official admissible limits for soil (Ministry of Environment, 1994). Albanese et al. (Chapter 24) cite intervention limits, established by Italian laws for soil use (D.M. 152/2006) and for sea sediment (D. M. 367/03) in their study of the Napoli region, Italy.

\section{COMMUNICATION}

The message or conclusions from an investigation of the chemical environment is not always, what people might want to hear. Telling a local population that they are living in a highly contaminated area with high risks to human health will undoubtedly cause anxiety amongst residents. It is also likely to affect detrimentally land and house prices, and place politicians in a difficult position. Several cases studies described here convey such messages.

Albanese et al. (Chapter 24) - “...results highlight the need for a remediation plan to be executed as soon as possible by the public authorities for the marine sediments, since thousands of citizens use the Bagnoli-Coroglio beach as a resort area during the summer."

Demetriades (Chapter 25) - "The rehabilitation of the greater Lavrion urban area environment is considered, therefore, an urgent task, otherwise alternate actions must be seriously examined, such as resettling the population in a better and healthier environment."

Applied geochemists are not always best placed to communicate such messages, and at the planning stage, it is always worth considering how the project conclusions will be disseminated and by whom. Many national geological surveys have an impartial national function to fulfil, and it can be quite damaging to be associated with delivering bad news. Communication is best handled through professional trained press officer.

At a lower and less contentious level, applied geochemists are increasingly being asked to share their geochemical data within multi-disciplinary projects, often with team members that have no understanding of chemistry. It is, therefore, important that we learn to communicate our geochemical results using maps than can be understood by the variety of stakeholders 
Final manuscript prepared for editing \& compilation - CCJ 15/3/2010 - AD updated 21/3/2010. Finalised ccj 21/03/10

who might use it. For example, rather than plotting element values or colour images by a range of percentile concentrations, it might be more helpful just to produce a simple colour coded map with a low, medium or high designation of the parameter we wish to convey.

Risk perception and communication is discussed by Demetriades (Chapter 11) demonstrating that mapping the chemical environment of urban areas can lead to very emotive issues. The "Beware of Soil Pollution Map" produced by the Environment Office of the City of Trondheim (Norway) (Chapter 12) is a good example of how geochemical data can be brought together with other information to raise awareness of the problems of soil pollution, and what should be done about it.

\section{FUTURE TRENDS}

The value of mapping the chemical environment, and the uses to which the data can be applied, are described in the chapters of this book. All urban areas need to have information about the local geochemical baseline, and be able to put it into the context of the "natural" background. There is no doubt that urban geochemical mapping of towns and cities will continue to be a high priority activity around the world. Countries with existing regional geochemical baseline maps can place the urban baseline into the context of these. There are also now available more continental or multinational scale geochemical maps that can be used for this purpose (e.g., Agricultural soil in Northern Europe - Reimann et al., 2003; Geochemical Atlas of Europe - Salminen et al., 2005; De Vos, Tarvainen et al., 2006) to provide background geochemical information. Several case studies in this volume have described that by extending surveys outside the urban limits useful "natural” background information can be provided. This can also be done by a transect through the urban area and out into the rural environs.

All cities of the world are unique, and will have their own particular environmental issues and will need a strategy for mapping the chemical environment that is adapted to address specific requirements. Nevertheless, the future trend must be one of more standardised sampling and analytical methodologies across political borders, led by initiatives, such as the Urban Geochemistry (URGE) project that is in the process of being initiated by the Geochemistry Expert Group of EuroGeosurveys. Once an urban baseline is established, geochemical mapping work progresses in two directions. Firstly, because anthropogenic activity can 
Final manuscript prepared for editing \& compilation - CCJ 15/3/2010 - AD updated 21/3/2010. Finalised ccj 21/03/10

change the chemical environment over a relatively short period of time, there is a requirement to monitor changes to the geochemical baseline. It is, therefore, desirable in cities where a geochemical baseline has been established to set up a network of sites for regularly monitoring changes to that baseline. Atmospheric and water monitoring networks are already common in many cities. Similar sites for monitoring soil, and other environmental media, should also be established. The second activity, which is a natural progression from the initial geochemical baseline mapping, is exploiting the data for the many applications to which they can be applied, and following-up specific areas of interest, i.e., more targeted investigations.

Urban geochemical baseline mapping will produce an archive of samples, and often more data and information than can be exploited by a national survey. The urban geochemical data and samples should be made readily available to other research organisations, such as universities, so that undergraduate or postgraduate projects can add value and information to the results and, thus, stimulate further research and development of methodologies. Targeted follow up of the baseline data needs to be focused to address some of the major environmental challenges of our time, and done as part of multidisciplinary teams. The work in Norway, targeting childcare centres and play areas, exemplifies such a focused approach, and helps to protect those most at risk, our children, from the chemical environmental hazards of the urban environment.

It is important to keep monitoring a broad range of chemicals in urban areas. Some chemical elements and organic compounds that are not considered a problem now may be discovered to have a hazardous role in the future. Furthermore, new technologies (e.g., mobile phones; electric cars; and increased use of nano-particles) will introduce new potentially hazardous chemical elements, and in different forms, to the urban environment. The systematic study of organic compounds has not received as much attention as the inorganic chemical elements. The presence of PCBs in exterior paint, and the potential risks they pose, as demonstrated by Norwegian studies, should receive much greater attention in the rest of the world.

The case studies in this book that have used a multi-media sampling approach have demonstrated the usefulness of using materials, other than soil, to map the distribution and behaviour of elements in the environment. Such materials, include mosses, road deposited sediment (RDS), house dust and snow cover. A multi-media approach can help our understanding of the movement and fluxes involved between the different environmental 
Final manuscript prepared for editing \& compilation - CCJ 15/3/2010 - AD updated 21/3/2010. Finalised ccj 21/03/10

compartments. More can be done to model the migration of contaminants through the urban environment - this has important consequences for protecting ground and surface water resources.

The chemical mapping of urban areas is only a part of the data gathering exercise, required to understand and protect the quality of the city environment. Geographical information systems, now readily available and accessible on affordable computers, allows us to integrate the geological, geochemical, geophysical, airborne gamma-ray spectrometry, land use, epidemiology, etc. layers of information in a way that we have not been able to do in the past. There is much work that can still be done on existing urban geochemical databases, using new information technologies, to produce value added maps (e.g., use of contamination indices and enrichment factors as described above), and to deliver the new information over the internet. The objective is to provide decision-makers and the public in general, with high quality geochemical baseline data to assess environmental contamination, but also to serve as a reference point in time against which future changes in the urban chemical environment can be measured.

\section{REFERENCES}

Albanese, S., Cicchella, D., Lima, A. and De Vivo, B., 2008. Urban Geochemical Mapping. In: De Vivo, B., Belkin, H. E., Lima, A., (Eds.), Environmental Geochemistry: Site characterization, Data analysis and Case histories. Elsevier, Amsterdam. Chapter 8, 153174.

BBodSchV (Bundes-Bodenschutz- und Altlastenverordnung), 1999. Bundes-Bodenschutzund Altlastenverordnung (BBodSchV) vom 12. Juli 1999. Bundesgesetzblatt, Bonn, Jahrgang 1999, Teil I Nr. 36 vom 16. Juli 1999, 1554 - 1582. In German.

Cicchella, D., De Vivo, B., Lima, A., Albanese, S., Mc Gill, R. A. R. and Parrish, R. R., 2008. Heavy metal pollution and $\mathrm{Pb}$ isotopes in urban soils of Napoli, Italy. Geochemistry: Exploration - Environment - Analysis, 8, 103-112.

Countryside Agency, 2004. Rural and Urban Area Classification 2004: An Introductory Guide. The Countryside Agency, England and Wales. Available on-line at: 
Final manuscript prepared for editing \& compilation - CCJ 15/3/2010 - AD updated 21/3/2010. Finalised ccj 21/03/10

http://www.statistics.gov.uk/geography/downloads/Introductory_Guide.pdf (Last accessed 22nd February 2010).

Darnley, A.G., Bjorklund, A., Bolviken, B., Gustavsson, N., Koval, P.V., Plant, J.A., Steenfelt, A., Tauchid, M. and Xuejing, X., 1995. A global geochemical database for environmental and resource management. UNESCO publishing, 19, 122 pp.

Davenport, P.H., Christopher, T.K., Vardy, S. and Nolan, L.W., 1993. Geochemical mapping in Newfoundland and Labrador: its role in establishing geochemical baselines for the measure of environmental change. Journal of Geochemical Exploration, 49, 177-200.

De Vos W., Tarvainen, T. (Chief Editors), Salminen, R., Reeder, S., De Vivo, B., Demetriades A., Pirc S., Batista, M.J., Marsina, K., Ottesen, R.T., O’Connor, P.J., Bidovec, M., Lima A., Siewers, U., Smith, B., Taylor, H., Shaw, R., Salpeteur, I., Gregorauskiene, V., Halamic, J., Slaninka, I., Lax, K., Gravesen, P., Birke, M., Breward, N., Ander, E.L., Jordan, G., Duris, M., Klein, P., Locutura, J., Bel-lan, A., Pasieczna, A., Lis, J., Mazreku, A., Gilucis, A., Heitzmann, P., Klaver, G. and Petersell, V., 2006. Geochemical Atlas of Europe. Part 2 Interpretation of Geochemical Maps, Additional Tables, Figures, Maps, and Related Publications. Geological Survey of Finland, Otamedia Oy, Espoo, 692 pp. Available online at http://www.gtk.fi/publ/foregsatlas/ - Last accessed on 21 $1^{\text {st }}$ March 2010.

EA, 2009. Using soil guideline values. UK Environment Agency. Science report: SC050021/SGV introduction. Available on-line at: http://www.environmentagency.gov.uk/static/documents/Research/SCHO0309BPQM-e-e.pdf (Last accessed 25th February 2010).

EC, 2006. Registration, Evaluation, Authorisation and Restriction of Chemical substances. European Community (EC) Regulation on chemicals and their safe use. Regulation (EC) No. 1907/2006. $18^{\text {th }}$ December 2006. Available online at: http://eurlex.europa.eu/LexUriServ/LexUriServ.do?uri=OJ:L:2006:396:0001:0849:EN:PDF (Last accessed $26^{\text {th }}$ February 2010).

EuroGeoSurveys, 2003. The Earth ... A Heritage, A Future. The Association of Geological Surveys of Europe, Brussels. 
Final manuscript prepared for editing \& compilation - CCJ 15/3/2010 - AD updated 21/3/2010. Finalised ccj 21/03/10

Fersman, A.E., 1935. The scientific study of Soviet mineral resources. Martin Lawrence Limited, London, 149 pp. (translated from Russian and edited by C.P. Dutt).

Finnish Government Decree, 2007. Government Decree on the Assessment of Soil Contamination and Remediation Needs (214/2007). In Finnish.

Fordyce, F.F., Brown, S.E., Ander, E.L., Rawlins, B.G., O’Donnell, K.E., Lister, T.R., Breward, N. and Johnson, C.C., 2005. GSUE: urban geochemical mapping in Great Britain. Geochemistry: Exploration - Environment - Analysis, 5, 325-336.

Grunsky, E.C., 2010. The interpretation of geochemical survey data. Geochemistry: Exploration-Environment-Analysis, 10(1), 27-74.

Hawkes, H.E. and Bloom, H., 1955. Heavy metals in stream sediment used as exploration guides. Mining Engineer, 8, 1121-1126.

Jelles, S.J., Makkee, M. and Moulijn, J.A., 2001. Ultra low dosage of platinum and cerium fuel additives in diesel particulate control. Topics in Catalysis, 16/17(1-4), 269-273.

Johnson, C.C. and Ander, E.L., 2008. Urban geochemical mapping studies: how and why we do them. Environmental Geochemistry and Health, 30, 511-530.

Lima, A., 2008. Evaluation of geochemical background at regional and local scales by fractal filtering technique: Case studies in selected Italian areas. In: De Vivo, B., Belkin, H. E., Lima, A., (Eds.), Environmental Geochemistry: Site characterization, Data analysis and Case histories. Elsevier, Amsterdam. Chapter 7, 135-152.

Lovering, T.S, Huff, L.C. and Almond, H., 1950. Dispersion of copper from the San Manuel copper deposit, Pinal County, Arizona. Economic Geology, 45, 493-514.

Matschullat, J., Ottesen, R. and Reimann, C., 2000. Geochemical background - can we calculate it? Environmental Geology, 39, 990-1000.

Ministry of Environment, 1994. Regulation 13/94 Coll. of the Ministry of Environment of the Czech Republic. In Czech.

Muller, G., 1981. Die schwermentallbelastung der sedimenten des neckars und seiner nebenflüsse. Chemiker-Zeitung, 6, 157-164. In German. 
Final manuscript prepared for editing \& compilation - CCJ 15/3/2010 - AD updated 21/3/2010. Finalised ccj 21/03/10

Nikolaidis, N., Demetriades, A., Papassiopi, N., Theodoratos, P., Vergou-Vichou, K., Vassiliades, E., Varelidis, N. and Zamani, A., 1999. Environmental management plan for the rehabilitation of soil in the Lavrion urban area. In: A. Demetriades (Editor), Soil Rehabilitation in the Municipality of Lavrion. Project "Soil rehabilitation in the Municipality of Lavrion”, EU LIFE programme Contract No.: 93/GR/A14/GR/4576. Institute of Geology and Mineral Exploration, Open File Report E8272, Athens, Hellas, Volume 4, 72-121.

OGRS, 1994. Book of Rules about the allowed amounts of dangerous and harmful substances in soil and water for irrigation and methods for their testing. Official Gazette of the Republic of Serbia, No. 23/94, Belgrade, Serbia.

OMG, 2010. We put metals where they need to be. OM Group website. Available online at: http://www.omgi.com/product-adv-fuel.html (Last accessed 25th February 2010).

Pasieczna, A., 2003. Atlas of urban soils contamination in Poland. Państwowy Instytut Geologiczny, Warszawa, 191 pp.

Plant, J.A., Klaver, G., Locutura, J., Salminen, R., Vrana, K. and Fordyce, F.M., 1997. The Forum of European Geological Surveys Geochemistry Task Group: geochemical inventory. Journal of Geochemical Exploration, 59, 123-146.

Presley, S.M, Rainwater, T.R, Austin, G.P, Platt, S.G., Zak, J.C., Cobb, G.P., Marsland, E.J., Tian, K., Zhang, B., Anderson, T.A, Cox, S.B., Abel, M.T., Leftwich, B.D., Huddleston, J.R., Jeter, R.M. and Kendall, R.J., 2006. Assessment of Pathogens and Toxicants in New Orleans, LA Following Hurricane Katrina. Environmental Science Technology, 40(2), 468-474. DOI: 10.1021/es052219p.

Reimann, C., Siewers, U., Tarvainen, T., Bityukova, L., Eriksson, J. Gilucis, A., Gregorauskiene, V., Lukashev, V.K., Matinian, N.N. and Pasieczna, A., 2000. Baltic soil survey: total concentrations of major and selected trace elements in arable soils from 10 countries around the Baltic Sea. The Science of the Total Environment, 257(2-3), 155-170.

Reimann, C., Siewers, U., Tarvainen, T., Bityukova, L., Eriksson, J., Gilucis, A., Gregorauskiene, V., Lukashev, V.K., Matinian, N.N. and Pasieczna, A., 2003. Agricultural 
Final manuscript prepared for editing \& compilation - CCJ 15/3/2010 - AD updated 21/3/2010. Finalised ccj 21/03/10

Soils in Northern Europe: A Geochemical Atlas. Geologisches Jahrbuch, Sonderhefte, Reihe D, Heft SD 5, Schweizerbart'sche Verlagsbuchhandlung, Stuttgart, 279 pp.

Reimann, C., Flem, B., Arnoldussen, A., Englmaier, P., Finne, T.E., Koller, F. and Nordgulen, Ø., 2008. The biosphere: A homogeniser of Pb-isotope signals. Applied Geochemistry, 23, 705-722.

Salminen, R. and Tarvainen, T., 1997. The problem of defining geochemical baselines. A case study of selected elements and geological materials in Finland. Journal of Geochemical Exploration, 60, 91-98.

Salminen, R. and Gregorauskienè, V., 2000. Considerations regarding the definition of a geochemical baseline of elements in the surficial materials in areas differing in basic geology. Applied Geochemistry, 15, 647-653.

Salminen, R., Tarvainen, T., Demetriades, A., Duris, M., Fordyce, F.M., Gregorauskiene, V., Kahelin, H., Kivisilla, J., Klaver, G., Klien, H., Larson, J.O., Lis, J., Locutura, J., Marsina, K., Mjartanova, H., Mouvet, C., O'Connor, P., Odor, L., Ottonello, G., Paukola, T., Plant, J. A., Reimann, C., Schermann, O., Siewers, U., Steenfelt, A., Van der Sluys, J., de Vivo, B. and Williams, L., 1998. FOREGS Geochemical Mapping Field Manual. Geological Survey of Finland, Guide 47. Available online at: http://arkisto.gtk.fi/op/op47/op47.pdf (Last accessed on $21^{\text {st }}$ March 2010).

Salminen, R., Batista, M.J., Bidovec, M., Demetriades, A., De Vivo, B., De Vos, W., Duris, M., Gilucis, A., Gregorauskiene, V., Halamic, J., Heitzmann, P., Lima, A., Jordan, G., Klaver, G., Klein, P., Lis, J., Locutura, J., Marsina, K., Mazreku, A., O'Connor, P.J., Olsson, S.Å., Ottesen, R.T., Petersell, V., Plant, J.A., Reeder, S., Salpeteur, I., Sandström, H., Siewers, U., Steenfelt, A. and Tarvainen, T., 2005. Geochemical Atlas of Europe. Part 1 Background information, methodology and maps. Geological Survey of Finland, Otamedia Oy, Espoo, 525 pp. (Available online at: http://www.gtk.fi/publ/foregsatlas/ (Last accessed on $21^{\text {st }}$ March 2010).

Swartjes, F.A., 1999. Risk-based assessment of soil and groundwater quality in the Netherlands: standards and remediation Urgency. Risk Analysis, 19, 1235-1249 
Final manuscript prepared for editing \& compilation - CCJ 15/3/2010 - AD updated 21/3/2010. Finalised ccj 21/03/10

Swedish EPA, 2008. Table of generic guideline values. Published October $24^{\text {th }} 2008$.

Available on-line at: http://www.swedishepa.se (Last accessed on 29 $9^{\text {th }}$ January 2010.

Tessier, A., Campbell, P.G.C. and Bisson, M., 1979. Sequential extraction procedure for the speciation of particulate trace metals. Analytical Chemistry, 51, 844.

Thornton, I., 1991. Metal contamination of soils in urban areas. In: Bullock, P. \& Gregory, P.J. (Eds), Soils in the Urban Environment. British Society of Soil Science. Chapter 4, 47 75. Blackwell Scientific Publications, Oxford.

Thornton, I. and Webb, J.S., 1979. Geochemistry and health in the United Kingdom. Philosophical Transactions of the Royal Society, B288, 151-168.

Tidball, R.R., Erdman, J.A. and Ebens, R.J., 1974. Geochemical baselines for sagebrush and soil, Powder River Basin, Montana Wyoming. US Geological Survey Open-file Report, Vol. 74-250, 6-13.

US Census Bureau, 1995. Urban and Rural Definitions. A note released October 1995. US Census Bureau, Washington, USA. Available on-line at: http://www.census.gov/population/censusdata/urdef.txt (Last accessed on $22^{\text {nd }}$ February 2010).

US Connecticut, 1997. State of Connecticut regulation of Department of Environmental Protection, Section 22a-133k-1, January 1997, 66 pp.

US EPA, 1996. Soil screening guidance: Technical background document. US Environmental Protection Agency, EPA/540/R-95/128, PB96-963502, Office of Solid Waste and Emergency Response, Washington, DC.

Webb, J.S. (Editor), 1978. The Wolfson geochemical atlas of England and Wales. Imperial College of Science and Technology. Applied Geochemistry Research Group. Clarendon Press, Oxford, 69 pp.

Wong, C.S.C., Li, X.D. and Thornton, I., 2006. Urban environmental geochemistry of trace metals. Environmental Pollution, 142, 1-16. 


\section{LIST OF TABLES}

Table 1: Classification of urban geochemical mapping studies into two groups (After Johnson and Ander, 2008)

Table 2: Summary of aims and objectives proposed for the urban geochemical mapping studies in this volume

Table 3: Summary of some European Commission (EC) Directives driving the demand for harmonised geochemical baseline data across political borders

\section{LIST OF FIGURES}

Figure 1: Map showing the geographical distribution of urban case studies described in this book (Map source: http://englishfreemap.jp)

Figure 2: Cartoon showing urban risks: imagine cities short of drinking water and where plants and trees cannot grow, because of polluted soil, where children cannot play outside. Urban areas, due to the population density and infrastructures are extra vulnerable to geological hazards (Source: EuroGeoSurveys, 2003. The Earth ... A Heritage, a Future)

Figure 3: Summary of depth of soil and overburden sampling described in the case studies of this book

Figure 4: Summary of frequency of chemical elements reported as being determined on soil and overburden samples in case studies described in this volume 
Final manuscript prepared for editing \& compilation - CCJ 15/3/2010 - AD updated 21/3/2010.

Finalised ccj 21/03/10

\section{TABLES}

\begin{tabular}{l|l}
\hline \multicolumn{1}{c|}{ SYSTEMATIC SURVEY } & \multicolumn{1}{c}{ TARGETED SURVEY } \\
\hline Entire urban area & Targeted land use/area \\
$\begin{array}{l}\text { Interpreted in the context of regional } \\
\text { geochemical baselines }\end{array}$ & Interpreted in the context of guideline values \\
$\begin{array}{l}\text { Ubiquitous sample medium } \\
\text { 100s - 1000s samples }\end{array}$ & Variety of sample media \\
$\begin{array}{l}\text { Full range of chemical elements }+/- \\
\text { organic compounds }\end{array}$ & Selected elements inorganic/organics \\
$\begin{array}{l}1 \sim 4 \text { samples per km }{ }^{2} \\
\text { Done by National/Public Organisations }\end{array}$ & \begin{tabular}{l} 
Done by Research Organisations/Universities \\
\hline
\end{tabular} \\
\hline
\end{tabular}

Table 1: Classification of urban geochemical mapping studies into two groups (After Johnson and Ander, 2008). 
Final manuscript prepared for editing \& compilation - CCJ 15/3/2010 - AD updated 21/3/2010.

Finalised ccj 21/03/10

\begin{tabular}{|c|l|}
\hline 1. & Provide municipalities with information that can be used in sustainable land management \\
\hline 2. & Distinguish between geogenic and anthropogenic sources \\
\hline 3. & Part of an information system for modelling hazards \\
\hline 4. & $\begin{array}{l}\text { Comparative investigation of the influence of potentially important source of diffuse anthropogenic } \\
\text { contamination }\end{array}$ \\
\hline 5. & $\begin{array}{l}\text { Obtain information that has practical applications in assessing risks and hazards to people within the } \\
\text { urban environment }\end{array}$ \\
\hline 6. & Study fate and transport of pollutants in urban soil \\
\hline 7. & Provided valuable databases for determining legal limits for contaminants in soil according to land use \\
\hline 8. & Provide a national capability in sampling urban areas \\
\hline 9. & $\begin{array}{l}\text { Urban samples and data are used in thematic environmental studies involving contaminated land, } \\
\text { ground water vulnerability and human health risk }\end{array}$ \\
\hline 10. & Provides a sample archive that can be used in science research, e.g., bioaccessibility studies \\
\hline 11. & $\begin{array}{l}\text { Geochemical maps are needed to display the natural trends of chemical elements in order to recognise } \\
\text { polluted areas }\end{array}$ \\
\hline 12. & A monitoring function relating to the chemical environment to fulfil a statutory role defined in legislation \\
\hline 13. & $\begin{array}{l}\text { Raising awareness of the significance of environmental protection through the timely delivery of high } \\
\text { quality information and education }\end{array}$ \\
\hline 14. & $\begin{array}{l}\text { Geochemical mapping forms an early part of environmental management system, necessary for the } \\
\text { remediation and eventual rehabilitation of contaminated land }\end{array}$ \\
\hline 15. & $\begin{array}{l}\text { Provides local geochemical baseline information that can be more practical and useful than national } \\
\text { guideline values }\end{array}$ \\
\hline 16. & $\begin{array}{l}\text { To provide information to the public in order to increases the awareness of environmental/ecological } \\
\text { challenges of the urban environment, which in turn supports a process to reduce and mitigate the risks } \\
\text { from contaminants }\end{array}$ \\
\hline 17. & $\begin{array}{l}\text { The geochemical information can be taken into account, when determining land prices and calculating a } \\
\text { tax to be levied on those causing pollution }\end{array}$ \\
\hline 18. & $\begin{array}{l}\text { To provide a reference point in time against which future changes to the urban chemical environment } \\
\text { can be measured }\end{array}$ \\
\hline
\end{tabular}

Table 2: Summary of aims, objectives and reasons proposed in support of urban geochemical mapping studies in this volume 


\begin{tabular}{l}
\hline \multicolumn{1}{c}{ Directive } \\
\hline EC Water Framework \\
Directive (WFD) \\
(2000/60/EC)
\end{tabular}

\author{
EC Integrated Pollution \\ Prevention and Control \\ Directive (IPPC) \\ (2008/1/EC), it replaces \\ Directive 96/61/EC
}

\begin{tabular}{l}
\hline EC Sewage Sludge \\
Directive (86/278/EEC)
\end{tabular}

Proposed EC Soil Directive
Summary ecological status for water quality objectives (except where deviations from the standard are justified); and to identify basic and supplementary measures to deal with point source and diffuse pollution. The directive will be managed on the basis of River Basin Districts (one or more drainage catchments). It has been created to implement the EC Integrated Pollution Prevention and Control Directive (96/61/EC). Its objective is to control pollution from industry.

This directive seeks to encourage the use of sewage sludge in agriculture, but regulates its use in order to protect the environment from its harmful effects.

Directive under consideration. The European Union included in the $6^{\text {th }}$ Environmental Action Programme the Thematic Strategy on Soil Protection that will lead in the future to an EU soil protection Directive.

\section{EC Mine Waste Directive (2006/21/EC)}

This proposed directive is seen as a supplementary measure to the WFD to minimise the adverse effects on the environment, caused by waste from the extractive industries.

EC Habitats Directive
(92/43/EEC)

This directive is concerned with the conservation of natural habitats and of wild fauna and flora.

\section{EC Landfill Directive (1999/31/EC)}

INSPIRE Directive
(2007/2/EC)

The Landfill (England and Wales) Regulations of 2002, implement the EC Landfill Directive which aims to prevent or reduce the negative environmental effects of landfill.

Establishing an Infrastructure for Spatial Information in the European Union for making available relevant, harmonised and quality geographic information to support formulation, implementation, monitoring and evaluation of policies and activities which have a direct or indirect impact on the environment.
Application of baseline geochemical data

Baseline geochemical data for low order streams can provide information about surface water quality for farmers and those who manage land. Regulatory bodies and administrators can use the data to determine guideline levels for elemental concentrations.

Baseline geochemical data can be used both by industry and regulators to assess the impact of polluting industries on the environment. The geochemical baseline data provide a reference point against which changes can be measured.

Baseline geochemical data can be used to monitor and model the impact on the environment of sewage sludge.

Geological surveys are the only organisations systematically sampling soil from urban areas, and can establish the urban geochemical baselines in order to assess the impact of human induced pollution.

Baseline geochemical data can be used to monitor and model the impact on the environment of mine waste.

Climatic or anthropogenic changes to the geochemistry of the surface environment that may impact on fauna and flora can be monitored using baseline geochemical data of the surface environment.

Baseline geochemical data can be used to monitor and model the impact on the environment of landfill.

Harmonised geochemical baseline data for the whole of Europe are needed in order to assess impacts on the environment.

\section{REACH Directive (EC 1907/2006) [Registration, Evaluation, Authorisation and Restriction of CHemical substances] - The new law entered into force on 1 June 2007.}

The aim of REACH is to improve the protection of human health and the environment through the better and earlier identification of the intrinsic properties of chemical substances. There is a need to fill information gaps to ensure that industry is able to assess hazards and risks of the substances, and to identify and implement the risk management measures to protect humans and the environment.
Baseline geochemical data are needed to establish the variable geochemical baseline across Europe, and the local maximum threshold values, against which any changes future changes can be monitored.

Table 3: Summary of some European Commission (EC) Directives driving the demand for harmonised geochemical baseline data across political borders 


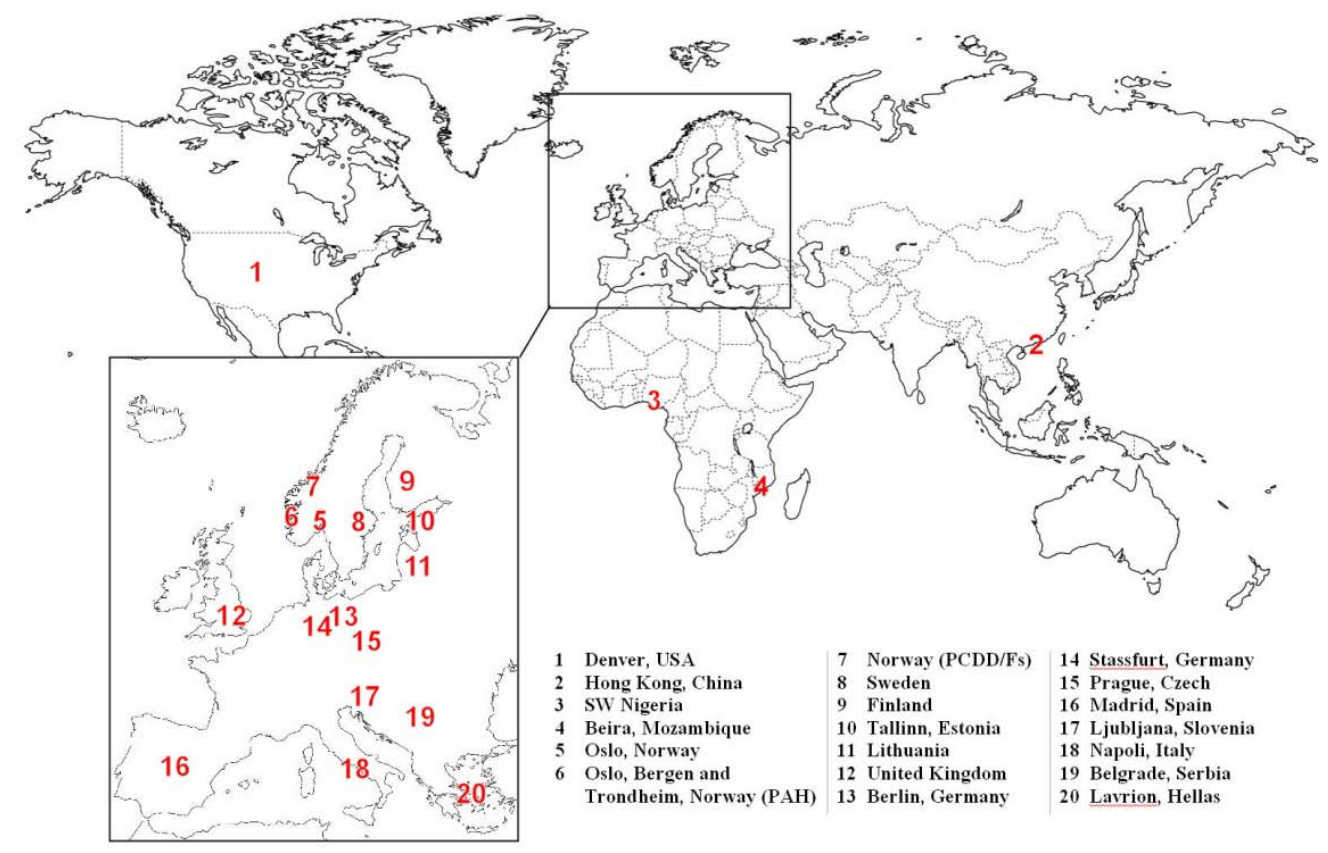

Figure 1: Map showing the geographical distribution of urban case studies described in this book (Map source: http://englishfreemap.jp)

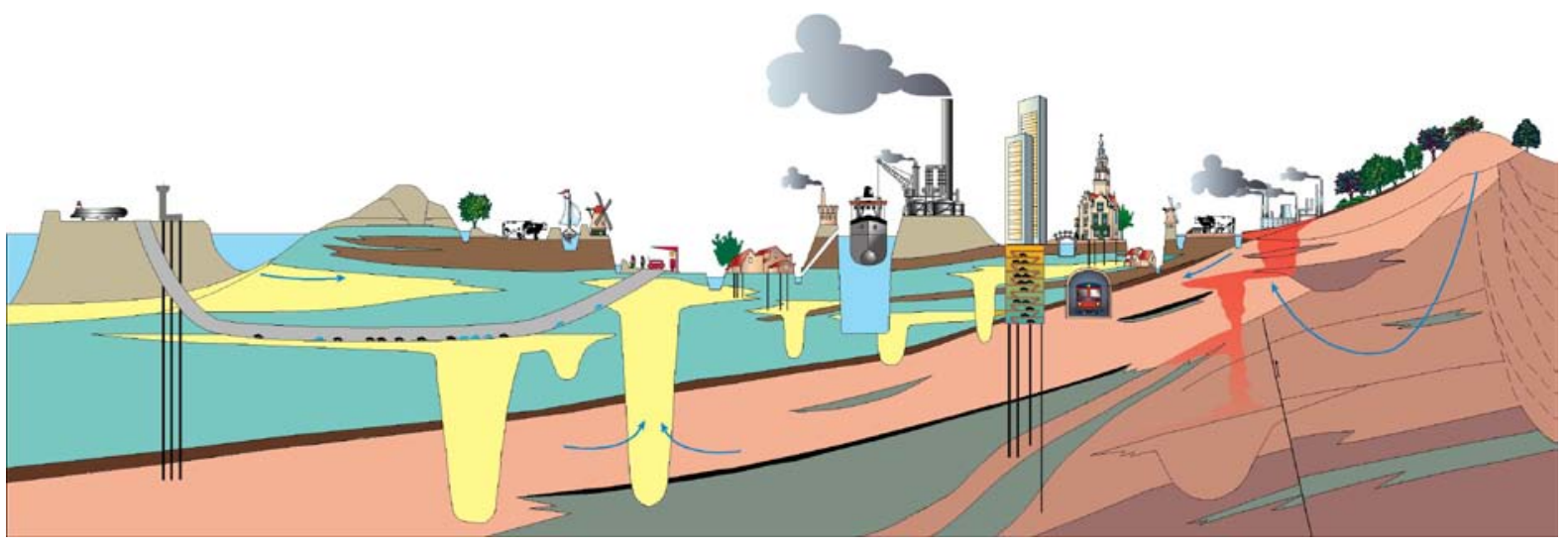

Figure 2: Cartoon showing urban risks: imagine cities short of drinking water and where plants and trees cannot grow, because of polluted soil, where children cannot play outside. Urban areas, due to the population density and infrastructures are extra vulnerable to geological hazards (Source: EuroGeoSurveys, 2003. The Earth ... A Heritage, a Future) 
Final manuscript prepared for editing \& compilation - CCJ 15/3/2010 - AD updated 21/3/2010.

Finalised ccj 21/03/10

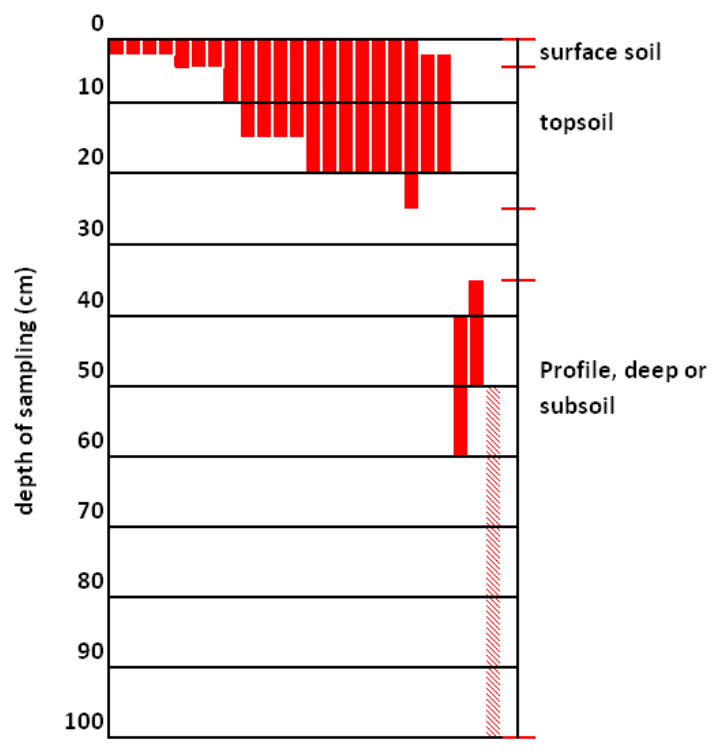

Figure 3: Summary of depth of soil and overburden sampling described in the case studies of this book. Each bar represents a case study, the deepest subsoil depths being typically indicative of the range from which a relatively undisturbed sample would be collected. 

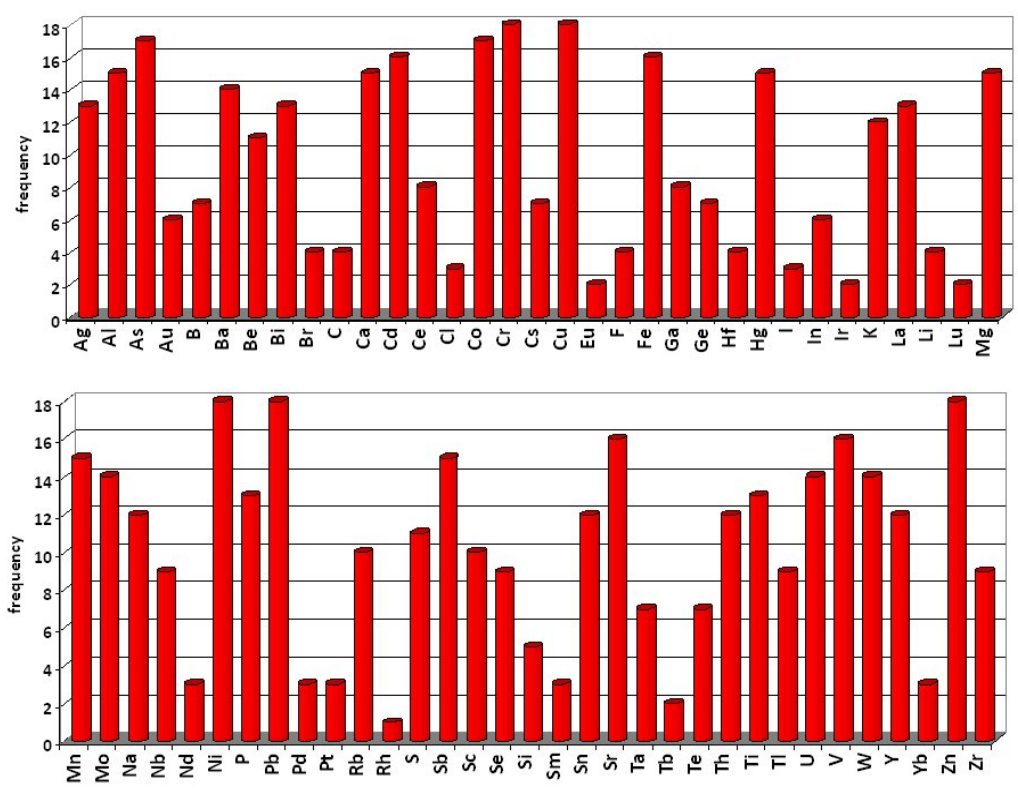

Figure 4: Summary of frequency of chemical elements reported as being determined on soil and overburden samples in case studies described in this volume 